\title{
Ethnic school composition and peer victimization: A focus on the interethnic school climate ${ }^{\text {is }}$
}

\author{
Orhan Agirdag ${ }^{\mathrm{a}, *}$, Jannick Demanet ${ }^{\mathrm{a}}$, Mieke Van Houtte ${ }^{\mathrm{a}}$, Piet Van Avermaet ${ }^{\mathrm{b}}$ \\ a Ghent University, Department of Sociology, Research Group CuDOS, Korte Meer 5, 9000 Gent, Belgium \\ ${ }^{\mathrm{b}}$ The Centre for Diversity and Learning, Ghent University, Sint-Pietersnieuwstraat 49, 9000 Gent, Belgium
}

\section{A R T I C L E I N F O}

\section{Article history:}

Accepted 8 September 2010

\section{Keywords:}

School segregation

Ethnic composition

Ethnic concentration

Ethnic heterogeneity

Victimization

Flanders

\begin{abstract}
A B S T R A C T
Does de facto school segregation have an impact on ethnic minority and majority pupils' chances of being victimized by their peers? Moreover, does the interethnic climate at school mediate the relationship between the ethnic school context and peer victimization? To answer these questions, this article examines the association between the ethnic composition of a school-as measured by the ethnic school concentration and the school's ethnic heterogeneity or diversity-and self-reported peer victimization. Multilevel analyses on data based on a survey of 2845 pupils (aged 10-12) in 68 Flemish primary schools revealed differential effects for natives and non-natives. In line with the imbalance of power thesis, and disconfirming the group threat theory, we find that non-native pupils report less peer victimization in schools with a higher minority concentration-that is, in schools with higher proportions of non-native pupils. Our findings indicate that this relationship is mediated by the interethnic school climate. In contrast, for native pupils, the concentration of ethnic minority students is not associated with peer victimization. We conclude by discussing the implications of these findings for the literature on interethnic relations and educational policy.
\end{abstract}

(c) 2010 Elsevier Ltd. All rights reserved.

\section{Introduction}

In many western countries, there is a growing concern about ethnic school segregation, as many recent studies have shown that a high concentration of ethnic minority students is unfavorable for educational achievement (for Belgium: Jacobs, Rea, \& Teney, 2009; for France: Felouzis, 2005; for Germany: Kristen, 2005; for the Netherlands: Westerbeek, 1999; Driessen, 2002; for Sweden: Szulkin \& Jonsson, 2006; for the United States: Bankston \& Caldas, 1996; Rumberger \& Palardy, 2005). Therefore, policy makers generally work towards the dispersal of immigrant and ethnic minority students (in this article we call these groups non-native pupils), believing that the mixing of students of different ethnic groups will enhance students' academic achievement and later occupational success (Burgess, Wilson, \& Lupton, 2005; Mahieu, 2002).

\footnotetext{
is Funding source: This research is funded by the Research Foundation Flanders (FWO-project G.040908). The Research Foundation Flanders had no involvement in the study design, in the collection, analysis and interpretation of data, in the writing of this report, or in the decision to submit the paper for publication.

* Corresponding author. Tel.: +32 926484 37; fax: +32 92646975

E-mail addresses: Orhan.Agirdag@Ugent.be (O. Agirdag), Jannick.Demanet@UGent.be (J. Demanet), Mieke.VanHoutte@UGent.be (M. Van Houtte), Piet.VanAvermaet@UGent.be (P. Van Avermaet).
} 
However, other studies have pointed to the flip side of this picture, arguing that school contexts with ethnically mixed student bodies might have unintended negative consequences for non-cognitive outcomes such as self-esteem and peer victimization (Gray-Little \& Hafdahl, 2000; Hanish \& Guerra, 2000). These non-cognitive outcomes are not only very important because pupils have the right to feel good at school, but also because they might have an impact on cognitive outcomes (Buhs \& Ladd, 2001). In other words, while attending ethnically mixed schools might have a positive impact on the educational performance of minority students, there will be no or fewer academic advantages when these students do not feel at home-if, for instance, they are frequently bullied in such school contexts. Research has shown that pupils who are victimized by their peers are more likely to face school adjustment and achievement difficulties (Buhs, Ladd, \& Gary, 2006). When educational policies do not take the potential adverse consequences of desegregation into account, they run the risk of failure. Therefore, educational research should identify and explain the potential negative effects of ethnic school composition on pupils' non-cognitive outcomes, in order to counteract them and make school desegregation efforts work.

In this study, we investigate the impact of de facto school segregation, as measured by the ethnic make-up of the school, on self-reported peer victimization. This paper is a unique contribution in three distinct ways. First, we consider three interdisciplinary theoretical frameworks, to achieve a better understanding of the association between the ethnic composition of a school and peer victimization. Specifically, we draw upon the imbalance of power thesis (Juvonen, Nishina, \& Graham, 2006), group threat theory (Blalock, 1967), and constrict theory (Putnam, 2007). Secondly, we employ a further elaborated conceptualization of ethnic school composition, as we make a clear distinction between ethnic minority concentration (the proportion of non-natives at school) and ethnic diversity or heterogeneity. Previous studies tended to confuse these two distinct concepts. Third, in Flanders-the Dutch-speaking region comprising the northern part of Belgium, where the present study was conducted-research into the effects of ethnic school composition on peer victimization is simply non-existent. Through this paper, we aim to fill these research lacunae.

\section{Ethnic composition and peer victimization}

Providing a thorough review of the research on bullying behavior and peer victimization, Espelage and Swearer (2003) insist that victimization should be understood through a social-ecological lens: it is imperative that we investigate both the individual characteristics of students and the context-level variables that may be responsible for increased chances of peer victimization. While the bulk of the research examined bullying behavior at the individual level (e.g., Ando, Asakura, \& Simons-Morton, 2005; Bowers, Smith, \& Binney, 1992; O’Moore \& Kirkham, 2001), less studies have focused on the ecological school factors. These studies found that the impact of a school's ethnic composition is an important context variable in reference to peer victimization (Graham, 2006; Hanish \& Guerra, 2000; Juvonen, Nishina, \& Graham, 2001; Juvonen et al., 2006; Verkuyten \& Thijs, 2002; Vervoort, Scholte, \& Overbeek, 2010). However, school ethnic composition has been operationalized in different ways. Some studies assess this by examining the ethnic heterogeneity of schools. For instance, a study by Rowe, Almeida, and Jacobson (1999) finds that displays of aggression by adolescents (aged 12-18), which often accompany bullying behavior, are more likely to emerge in schools with more heterogeneity. But a number of different studies come to another conclusion. Graham (2006) and Juvonen et al. (2006), for example, demonstrated that pupils (aged 10-12) at more heterogeneous schools are less likely to be victimized, and that this holds for both for ethnic minority and majority students.

Other studies operationalize ethnic school composition as the proportion of non-natives in a school. Again, the empirical evidence here points in different directions. A Dutch study by Vervoort et al. (2010) found that school classes with higher proportions of non-natives saw more victimization for both natives and non-native pupils (aged 12-14) than school classes with fewer non-natives. Verkuyten and Thijs (2002), in contrast, showed that native and non-native pupils (aged 10-14) felt more victimized when they attended schools classes with respectively fewer native and non-native peers. Research in the United States concurs with this latter study: pupils (aged 10-12) who are in a numerically minority position at school are at a heightened risk of being victimized (Juvonen et al., 2001). Hanish and Guerra (2000), in a study in the United States with elementary school pupils (aged 6-10), complete the confusion, as they show that schools where ethnic group sizes are roughly equal foster more victimization for White children and less for African-American children, and have no effect on the victimization rates of Hispanic children.

These findings show that the relation between ethnic school composition and peer victimization is a rather complex one, and that researchers have not come to an understanding of the direction of the relationship. Matters are complicated further because studies have not assessed this in a coherent manner. As discussed above, some studies operationalize ethnic composition as the proportion of students from a certain ethnic group-we call this the ethnic minority concentration in schools (e.g., Juvonen et al., 2001; Verkuyten \& Thijs, 2002; Vervoort et al., 2010); however, others use a calculated index of heterogeneity - that is, the number of distinct ethnic groups within a body of students (e.g., Graham, 2006; Juvonen et al., 2006). This renders their results difficult to compare. Moreover, although this issue is clearly situated on two different levels-ethnic composition at the school level, and peer victimization at the student level-there are studies that use singlelevel techniques (e.g., Hanish \& Guerra, 2000), though it is imperative to use multilevel analysis to resolve this (see Graham, 2006; Verkuyten \& Thijs, 2002). It is important to address these matters in a coherent way, as it is possible that these differing choices are to some degree responsible for the divergent results. 


\section{Theoretical background}

To get a better understanding of the relationship between the ethnic composition of a school and peer victimization, we will successively consider three theoretical frameworks: the imbalance of power thesis, group threat theory, and constrict theory.

\subsection{The imbalance of power thesis}

Victimization is defined as physical, verbal, or psychological abuse that takes place in or around school (Arora, 1996; Graham, 2006). Different authors argue that the most defining characteristic of this form of peer harassment is an imbalance of power between the perpetrator and the victim. This definition has been used to explain the finding that peer victimization is more likely to occur in contexts where a certain ethnic group is much larger than another group (Graham, 2006; Juvonen et al., 2006). We refer to this explanation as the imbalance of power thesis. According to this view, the power of a certain group in a school context is partly determined by the relative number of group members. This is especially the case for ethnic groups, as a student's ethnicity itself can be a power marker (Vervoort et al., 2010). The implication of this view on victimization is that students are more likely to be victimized by other students when their ethnic group is much smaller the ethnic group of the perpetrators. As such, the proportion of natives and non-natives at school can be expected to be related to the rates of victimization of non-natives and natives, respectively. This is in accord with the observation that people who stand out in a certain setting-homosexual youths in a predominantly heterosexual setting, for example-are found to be more at risk of victimization (Nadeem \& Graham, 2005; Wright, Giammarino, \& Parad, 1986). This latter viewpoint is also known as the misfit theory. Thus, we arrive at the following hypothesis:

H1. A higher proportion of non-native pupils at school will result in lower levels of reported peer victimization for nonnative pupils and higher levels of reported peer victimization for native pupils, and vice versa.

\subsection{Group threat theory}

The imbalance of power thesis counters the well-established theoretical approach of group threat theory (Blalock, 1967). This theory also posits that ethnic group size leads to dominance in a school context, but draws different conclusions. According to group threat theory, various ethnic groups want to gain and defend control over the school setting. Early group threat theory started from the viewpoint of members of the dominant ethnic group, stating that they feel threatened when the number of immigrants in a certain context is large (Blalock, 1967). As a reaction, more interethnic conflict ensues as the dominant group members defend their own status. This first version of the theory stated that interethnic group conflict rises linearly with increasing numbers of ethnic minority students (Blalock, 1967).

However, this assumption was questioned by certain researchers, who focused on all ethnic groups, not just the dominant group (Longshore, 1982; Goldsmith, 2004). They showed that the relation is curvilinear: feelings of ethnic threat are not more intense in contexts where ethnic minority pupils are overrepresented, but rather in contexts where the different ethnic groups are of roughly equal size, as the power structure is not clear in such situations. As a result, an interethnic conflict arises to determine which group controls the "turf." Various studies have shown that antisocial behavior can be an effective means of gaining social dominance (Demanet, 2008; Hawley, 1999; Nadeem \& Graham, 2005). As such, students of one ethnic group have a larger chance of being victimized in such fifty-fifty contexts, because their control over the school situation is contested by the other group. Hence, we can expect that the amount of victimization is largest in settings with equally sized ethnic groups, and this generates the following hypothesis:

H2. When the proportion of non-native pupils at a school is around $50 \%$, higher levels of reported peer victimization can be expected for both native and non-native pupils.

\subsection{Constrict theory}

The hypotheses described above are related to ethnic minority concentration-that is, to the proportion of non-native pupils at school. But, as already mentioned, while minority concentration is often confused with ethnic diversity, these are actually two distinct concepts and two distinct measurements of ethnic composition (see Chan \& Birman, 2009; Putnam, 2007). Ethnic diversity or heterogeneity refers to the spectrum of ethnic difference in a given context. To conceptualize the impact of ethnic diversity at the school level, consider the constrict theory as described by Putnam (2007). According to this theory, the amount of ethnic diversity in a given context triggers social anomie or social isolation. In ethnically diverse environments, Putnam states, people will be less engaged in collective actions and will have fewer close friends, with declining solidarity and trust in others as result. It should be noted that Putnam states that this happens only in the short run; in the long term, there are wider benefits of ethnic diversity.

Constrict theory can apply to both an ethnic minority and the ethnic majority. The original constrict theory took neighborhoods as units of contextual analysis, while we will test it in a school context. Similarly, the original constrict theory does not link ethnic diversity or heterogeneity directly to victimization, but rather to solidarity and trust relations. However, we 
hypothesize that declining solidarity and trust relations in schools with more heterogeneity might lead to increasing peer victimization:

H3. Ethnic heterogeneity at the school level will increase reported peer victimization of both native and non-native pupils.

\subsection{Interethnic school climate as mediator}

The school-effects literature underlines the importance of a mediation model. These are mediator variables, such as school culture and climate, that might explain or suppress the impact of structural school variables such as ethnic composition (for reviews, see Teddlie \& Reynolds, 2000; Van Houtte, 2005). Similarly, the theories described above contend that the relation between ethnic composition and peer victimization is not a mechanical one, but is mediated. Particularly, the importance of interethnic relations is discussed. For instance, the imbalance of power thesis associated ethnic composition with ethnic groups having greater power at school; similarly, group threat theory related ethnic composition with emerging interethnic conflict, as different ethnic groups perceive each other as a threat to school control. In this paper, we conceptualize these interethnic relations at the school level as the interethnic school climate, measured by the amount of interethnic friendships and interethnic conflict at school. It should be noted that there exist other conceptualizations of climate as well (e.g. Dansby \& Landis, 1996). Our conceptualization of climate is rather deduced from the climate notions within the school-effects literature (Van Houtte, 2005).

A number of studies have linked the ethnic makeup of a school to the amount of interethnic friendship and conflict that takes place inside the school walls (Chan \& Birman, 2009; Fischer, 2008; Goldsmith, 2004; Van Houtte \& Stevens, 2009). School climates characterized by conflict, in turn, can evoke more antisocial behavior in their students (Kasen, Johnson, \& Cohen, 1990; Kuperminc, Leadbeater, Emmons, \& Blatt, 1997; Kuperminc, Leadbeater, \& Blatt, 2001). Hence, the relationship between ethnic school composition and interethnic school climate on the one hand, and the association between interethnic school climate and peer victimization on the other, leads us to the following mediation hypothesis:

H4. The impact of ethnic composition on reported peer victimization will be mediated by interethnic school climate-that is, by the amount of interethnic friendship and interethnic conflict at the school level.

\section{Methods}

\subsection{Sample}

We used data gathered in 2008 and 2009 from 2845 pupils in a sample of 68 primary schools in Flanders as part of the Segregation in Primary Education in Flanders (SIPEF) project. Multistage sampling was conducted. In the first instance, in order to encompass the entire range of ethnic composition, we selected three cities in Flanders with ethnically diverse populations. Second, using data gathered from the Flemish Educational Department, we chose 116 primary schools within these selected cities and asked them to participate; $54 \%$ of the schools agreed to do so. The school non-response rate was relatively high because Flemish schools are commonly swamped with such requests from investigators, to which they generally agree on a first come, first served basis. As such, the participating schools did not differ from those that opted out in terms of school sector (i.e., private vs. public schools) or ethnic composition (as measured by the proportion of nonnative pupils). The schools in this dataset encompass the entire range of ethnic composition, from schools having almost no non-native pupils to pure minority-concentrated schools with $100 \%$ non-native pupils.

Within these schools, our research team asked all fifth-grade pupils present at school during our visit to fill out a written questionnaire. If there were fewer than 30 fifth-grade pupils, we surveyed all the sixth-grade pupils as well. The pupils completed the questionnaires in class in the presence of one or two researchers. A total of 2845 pupils (with a mean age of 11.61) completed the questionnaire. The questionnaires were anonymous and were analyzed in complete confidentiality.

\subsection{Research design}

Given that we are dealing with a clustered sample of pupils nested within schools and with data at different levels-namely, variables of ethnic school composition as the main determinants at the school level and reported peer victimization as outcome at the pupil level-the use of hierarchical linear modeling is most appropriate. More specifically, we used two-level, random intercept, random slope multilevel modeling (SAS PROC MIXED, Singer, 1998). As is common in multilevel analyses, we first estimated an unconditional model to determine the amount of variance in peer victimization that occurs between schools (see Section 4.3). We tested Hypotheses 1 and 2 with Model 1, Hypothesis 3 with Model 2 and Hypothesis 4 with Model 3. We calculated cross-level interactions with ethnicity, since we hypothesized that the association between ethnic school composition and self-reported peer victimization would be different for native and non-native pupils. 
Table 1

Descriptive statistics for variables: frequency, minimum, maximum, mean or proportion, standard deviation (SD).

\begin{tabular}{|c|c|c|c|c|c|}
\hline & $N$ & Min & Max & Mean or \% & SD \\
\hline \multicolumn{6}{|l|}{ School-level } \\
\hline Ethnic concentration & 68 & 2.631 & 100 & 51.500 & 34.164 \\
\hline Ethnic diversity & 68 & -0.875 & -0.177 & -0.461 & 0.198 \\
\hline Interethnic conflict climate & 68 & 1.142 & 2.851 & 2.130 & 0.351 \\
\hline Interethnic friendship climate & 68 & 1.121 & 3.102 & 2.286 & 0.399 \\
\hline \multicolumn{6}{|l|}{ Pupil-level } \\
\hline Ethnicity ( 1 = non-native) & 2845 & 0 & 1 & $47.73 \%$ & \\
\hline Grade $(1=$ sixth $)$ & 2845 & 0 & 1 & $29.98 \%$ & \\
\hline Gender ( 1 = girl $)$ & 2827 & 0 & 1 & $51.54 \%$ & \\
\hline SES & 2823 & 0 & 8 & 4.232 & 2.372 \\
\hline \multicolumn{6}{|l|}{ Outcome } \\
\hline Peer victimization & 2594 & 1 & 5 & 1.878 & 0.869 \\
\hline
\end{tabular}

\subsection{Variables}

\subsubsection{Outcome}

To measure the extent of peer victimization, we used a self-reported three-item scale (see Espelage \& Swearer, 2003). More specifically, we asked pupils to state how frequently they (a) are bullied at school, (b) are called names at school, and (c) are excluded at school by their peers. There were five possible answers: (1) never, (2) almost never, (3) sometimes, (4) often, and (5) very often. Scores of these three items were averaged, and this scale yielded a Cronbach's alpha of 0.84 (see Table 1 for descriptive statistics). Justifying the need for multilevel analyses, we found that a significant amount of the variance in peer victimization is between schools $(3.83 \%, p<0.001)$, computed as the between-school variance component divided by the sum of within-school and between-school variance $\left(\tau_{0} /\left(\sigma^{2}+\tau_{0}\right)\right)$.

\subsubsection{Individual-level variables}

Four individual-level variables were included in the multilevel analyses. With respect to ethnicity, the principal criterion was the birthplace of the pupils' grandmothers. If these data were missing, we considered pupils' parents' birthplaces, as most non-native pupils in Flanders are second- or third-generation immigrants. We consider eleven broad ethnic groups: Native Belgians (46.7\%), Western Europeans, including pupils of Dutch, French, or German origin (5.6\%), Southern Europeans, including pupils of Italian or Spanish origin (6.6\%), Turks (13.0\%), Moroccans (15.6\%), Other North Africans (1.0\%), Eastern Europeans (5.8\%), Sub-Saharan Africans (1.8\%), Middle Easterners (1.2\%), Southeast Asians (1.7\%), Others (1.1\%). As is common practice, and in line with the official Flemish definition of non-native groups, students of Western European origins (group 1 and 2) were considered to be of native descent (see Agirdag, 2009; Van Houtte \& Stevens, 2009). As such, we created a dichotomous variable ( 0 = native, $1=$ non-native) and $47.73 \%$ of our respondents are categorized as non-native (see Table 1 ). Our research concentrated on fifth- and sixth-grade pupils (with 1992 and 853 pupils studied, respectively). Therefore, most of the respondents were aged 11 (about 49\%) or 12 (about 36\%) in 2009. Given the strong association between age and grade (Cramer's $V=0.64 ; p<0.001$ ), we had to choose one of these two variables to enter into the model. Because the sample was unbalanced for grade, we opted for the latter. The sample was equally divided with respect to gender, with around $51 \%$ of the respondents being female (boy = 0 , girl=1). Finally, we measured the socioeconomic status (SES) of the pupils by means of the occupational prestige of the father and mother (Erikson, Goldthorpe, \& Portocarero, 1979); the higher of the two is used as an indicator of the SES of the family. The respondents have a mean SES of $4.232(S D=2.372$; Table 1).

\subsubsection{School-level variables}

As stated above, the school ethnic composition is measured by two indicators. First, we consider the ethnic minority concentration-that is, the proportion of non-native respondents in a school in our database. On average, the proportion of non-native pupils is $51.50 \%$, and ranges from $2.631 \%$ to $100 \%$ non-native pupils (see Table 1 ). As part of the survey, the school administrators were asked to estimate the proportion of non-native pupils within their school. A Pearson correlation of $0.81(p<0.001)$ was calculated between the administrators' estimate and the proportion of non-native respondents to the survey; this validates the data-derived measure. Because Hypothesis 2 predicts a curvilinear relationship (i.e., peer victimization being most prevalent in schools with about $50 \%$ non-natives or natives), we enter a quadratic term of minority concentration as well, that is, we squared the original ethnic concentration. Grand mean centering is used to avoid multicollinearity.

The second indicator of ethnic school composition measures the ethnic diversity or heterogeneity within a school, expressed as the total number of different groups of non-natives, corrected by their size. Following Lancee and Dronkers (2010), we used as an index of ethnic diversity the Herfindahl index as used by Putnam (2007), though we multiplied this by -1, as Putnam (2007) in fact calculated an index of homogeneity, whereas we are interested in heterogeneity. The index used as is calculated as $\left(p_{\text {ethnic group } 1}\right)^{2}+\left(p_{\text {ethnic group } 2}\right)^{2}+\ldots+\left(p_{\text {ethnic group } n}\right)^{2}$. We included the eleven ethnic groups listed above. The index has a range of -1 to 0 ; a value of -1 implies no diversity at all-that is, there is only one ethnic group enrolled in the 
School-level, cross-level and pupil-level influences on peer victimization (multilevel analysis): standardized gamma coefficients and standard errors.

\begin{tabular}{|c|c|c|c|c|c|c|}
\hline & \multicolumn{2}{|l|}{ Model 1} & \multicolumn{2}{|l|}{ Model 2} & \multicolumn{2}{|l|}{ Model 3} \\
\hline & $y$ & SE & $y$ & SE & $y$ & SE \\
\hline \multicolumn{7}{|l|}{ School-level } \\
\hline Ethnic concentration & .000 & .055 & & & -.091 & .083 \\
\hline Squared ethnic concentration & -.090 & .051 & & & .086 & .096 \\
\hline Ethnic diversity & & & .033 & .031 & & \\
\hline Interethnic conflict climate & & & & & $.164^{* *}$ & .058 \\
\hline Interethnic friendship climate & & & & & .073 & .096 \\
\hline \multicolumn{7}{|l|}{ Interactions with ethnicity } \\
\hline Ethnic concentration & $-.093^{*}$ & .044 & & & -.050 & .066 \\
\hline Squared ethnic concentration & .085 & .067 & & & -.007 & .130 \\
\hline Interethnic conflict climate & & & & & -.009 & .051 \\
\hline Interethnic friendship climate & & & & & -.070 & .078 \\
\hline \multicolumn{7}{|l|}{ Pupil-level } \\
\hline Ethnicity (1 = non-native) & $-.108^{* * *}$ & .037 & $-.095^{* * *}$ & .026 & -.047 & .082 \\
\hline Grade $(1=$ sixth $)$ & $-.109^{* * *}$ & .024 & $-.118^{* * *}$ & .025 & $-.102^{* * *}$ & .025 \\
\hline Gender $(1=$ girl $)$ & -.021 & .020 & -.022 & .020 & -.019 & .020 \\
\hline SES & $-.108^{* * *}$ & .026 & $-.095^{* * *}$ & .025 & $-.105^{* * *}$ & .026 \\
\hline
\end{tabular}

${ }^{*} p \leq 0.05$.

** $p \leq 0.01$.

${ }^{* * *} p \leq 0.001$.

school. A value approaching zero means total diversity: each pupil in the school has a different ethnic origin. In our data, on average, schools have a value of $-0.461(S D=0.198$, Table 1$)$.

To conceptualize the interethnic friendship climate, we asked native respondents to state how many of their friends at school had a non-Belgian origin, and we asked non-native pupils to state how many of their friends at school had a Belgian origin. There were five possible answers: (1) nobody, (2) a few, (3) half of them, (4) most of them, and (5) all of them. To determine interethnic friendship climate scores, the pupil-level scores were aggregated by calculating the mean at the school level. In our data, on average, there was a mean school interethnic friendship climate value of $2.286(S D=0.399$; Table 1).

We used a similar measurement for interethnic conflict climate. We asked native respondents to state how often they have conflicts or quarrels at school with peers of non-Belgian origin, and we asked non-native pupils to state how often they have conflicts or quarrels at school with peers of Belgian origin. There were five possible answers: (1) never, (2) almost never, (3) sometimes, (4) often, and (5) very often. To determine climate scores, these interethnic conflict scores at the pupil level were aggregated by calculating the mean scores at the school level. As Table 1 shows, on average, schools have an interethnic conflict climate value of $2.130(S D=0.351)$. Interethnic conflict climate correlated $0.67(p<0.001)$ with interethnic friendship climate. While this positive correlation might sound surprising at first glance, previous studies also found such a positive relation between friendliness and conflict (for a detailed investigation, see Goldsmith, 2004). For the sake of clarity, it should be noted that interethnic conflict climate and the outcome variable (i.e., peer victimization) are conceptually two distinct measures. While the former is explicitly related to interethnic quarrels and is situated at the school level, the outcome variable measures victimization in general and is situated at the pupil level. These two concepts also differ statistically, as the Pearson correlation between them is rather moderate $(0.11 ; p<0.001)$.

\section{Results}

\subsection{Hypothesis 1}

Model 1 (Table 2) indicates that for native pupils the ethnic school concentration is not significantly related to peer victimization $\left(\gamma^{*}=.000, p=.995 ; \gamma^{*}\right.$ is the standardized gamma coefficient). However, non-native pupils attending schools with a higher ethnic minority concentration tend to report less peer victimization than those attending schools with fewer non-natives $\left(\gamma^{*}=-.093 ; p<0.05\right)$. Hence, Hypothesis 1 is only supported with respect to non-native pupils.

While the pupil-level effects are not the primary concern of this article, it is worth mentioning that non-native pupils, pupils in the sixth grade, and pupils with a higher SES report less victimization than native pupils, pupils in the fifth grade and pupils with lower SES.

\subsection{Hypothesis 2}

Model 1 (Table 2) indicates that for both groups of pupils, there is no evidence for a curvilinear relationship as the squared ethnic concentration variable is not significantly related to victimization. Hence, Hypothesis 2 is not supported. 


\subsection{Hypothesis 3}

Unlike ethnic concentration, ethnic diversity/heterogeneity does not have an impact. As indicated by Model 2 (Table 2), our measurement of ethnic diversity/heterogeneity is not significantly related to pupils' peer victimization. Therefore, Hypothesis 3 is not supported.

\subsection{Hypothesis 4}

Hypothesis 4 states that the impact of the ethnic school context will be moderated by the interethnic school climate. Model 3 (Table 2) includes the amount of interethnic conflict and friendship at the school level. While interethnic conflict climate is positively related to peer victimization $\left(\gamma^{*}=.164 ; p<.01\right)$, interethnic friendship climate is not significantly associated with peer victimization $\left(\gamma^{*}=.074 ; p=.0449\right)$. The cross-level interaction terms with ethnicity demonstrate that the impact of interethnic school climate is not different for natives and non-natives. Most importantly, the addition of the interethnic school climate variables alters the effect of minority concentration (see Model 1), as the impact of ethnic minority concentration for non-native pupils drops to an insignificant level $\left(\gamma^{*}=.050 ; p=0.467\right)$. This suggests that, the interethnic climate of the school indeed mediates the association between ethnic minority concentration and peer victimization. Hence we find support for Hypothesis 4.

\section{Discussion and conclusion}

The purpose of this study was to investigate the effects of de facto school segregation on peer victimization. Therefore, we examined the association between the ethnic composition of a school and the extent of pupils' reported peer victimization. The merit of this study is twofold: we made contributions to the literature on peer victimization (see Section 6.3) and provided new insights for educational policies on segregation. Our findings were noticeably different for natives and nonnative pupils; thus, we discuss these findings separately for both groups, together with their implications for educational policy.

\subsection{Non-native pupils}

With regard to non-native pupils, our results suggest that there is a negative relationship between the proportions of non-natives at school-we called this the ethnic minority concentration-and self-reported peer victimization. Thus, we find support for the imbalance of power thesis (Hypothesis 1). In contrast, none of our evidence favors the group threat theory (Hypothesis 2), that is, in schools where the proportion of native and non-native pupils is roughly equal, no higher rates of peer victimization are reported. We found no support for Hypothesis 3, which we derived from the constrict theory, as ethnic diversity/heterogeneity is not associated with peer victimization. Further, our findings partly endorse Hypothesis 4 . The amount of interethnic conflict at the school level is responsible for the association between ethnic minority concentration and peer victimization; however, our second measurement of interethnic school climate, the amount of interethnic friendship, was not related to self-reported peer victimization.

These findings have considerable implications for educational policy. Policy makers generally work towards the dispersal of non-native pupils to improve their academic achievement; more generally, there is a preference for non-segregated schools. However, this study revealed that, in school settings with a lower ethnic minority concentration, non-native pupils might be at higher risk of being victimized than in schools where non-natives constitute a numerical majority. This does not mean that school desegregation automatically leads to higher rates of victimization for non-native pupils. In contrast, we showed that, if the interethnic school climate is taken into account, ethnic composition does not impact peer victimization. Therefore, if policy-makers strive for educational desegregation-in order to improve academic achievement, for instance-they should also consider improving interethnic school climate in desegregated schools.

\subsection{Native pupils}

With respect to native pupils, the results indicate that ethnic composition variables are not related to reported peer victimization. Therefore, we should ask why the imbalance of power thesis (Hypothesis 1 ) holds true for non-natives only. One potential post hoc explanation: even when native pupils constitute a proportional minority in the school, they are still the numerical majority and socially dominant group within the broader society. Hence, their lack of numerical power in those school settings is probably compensated by their social and numerical majority position in the broader society (for a more elaborated discussion, see Van Houtte \& Stevens, 2009; Verkuyten \& Thijs, 2002).

These findings should also be linked to educational desegregation policies. Currently, there are government-subsidized programs to make ethnic minority concentrated schools more attractive for middle-class native parents (e.g., Albertijn \& Smeyers, 2009). It is argued that middle-class native parents avoid enrolling their children in such schools because they are concerned about the academic achievement and well-being of their children. As most research on ethnic segregation has focused on the impact on non-native pupils, it is not clear whether native parents are rightfully concerned. However, this 
study demonstrated that neither ethnic minority concentration nor ethnic heterogeneity have an effect on the self-reported victimization rates of native pupils.

\subsection{Limitations of this study, and directions for future research}

There are previous studies that have focused on the impact of the ethnic school context on peer victimization as well. These studies investigated peer victimization of pupils in the same age range as our sample (Graham, 2006; Juvonen et al., 2006; Verkuyten \& Thijs, 2002), in older pupils (Rowe et al., 1999; Vervoort et al., 2010) and in younger pupils (Hanish \& Guerra, 2000). The results of studies by Hanish and Guerra (2000), Verkuyten and Thijs (2002) and Vervoort et al. (2010) equally found support for the imbalance of power thesis. However, it should be noted that Verkuyten and Thijs (2002) studied the impact on racist peer victimization, while other studies, including the present study, have focused on (non-ethnic) peer victimization. Nevertheless, it might be the case that the ethnic school context is more strongly associated with racist peer victimization than it is associated with (non-ethnic) victimization in general. Hence, we suggest that future research should measure the effects on both, non-ethnic victimization and racist victimization. With respect to our second measurement of ethnic school context, the ethnic heterogeneity, the findings of this study contradict some previous studies, which found higher or lower levels of victimization in more heterogeneous school settings (Juvonen et al., 2006; Rowe et al., 1999).

It is important to keep in mind a few weaknesses of this study. First, we made a raw distinction between native and non-native pupils. This distinction neglects the ethnic differences within the non-native group. However, a separate analysis for each ethnic minority group would have harmed the reliability of our analysis, because the individual groups in our data are too small. Nevertheless, to be sure that the native and non-native categories are internally more or less homogenous, we did not include children from West-European origins within the non-native category, as West-Europeans are commonly considered to be more comparable to natives. While considering non-natives as one category is consistent with most of the previous studies conducted in Belgium and the Netherlands (e.g., Agirdag, 2010; Jacobs et al., 2009; Vervoort et al., 2010), future research should, if possible, make a distinction within the non-native groups. A second potential drawback of this study is that we only considered the influence of school-level and pupil-level variables and failed to include any class-level variables. However, we did this because our sample was not suitable for running a three-level, random-intercept, randomslope model, and the focus of the research project is on the impact of school ethnic composition. Third, this investigation employs a limited measure of interethnic friendship. We asked all pupils to state how many of their friends were natives and non-natives, and provided them with five answering categories (ranging from "none of them" to "all of them"). However, with this measure we cannot control for the true size of interethnic friendship networks. A more elaborated technique would be to provide pupils a list with the names of all pupils at school and to ask to indicate their friends. However, such a technique was unsuitable not only because the survey would have needed a higher time investment, but mainly because it was completely anonymous.

With regard to the literature, this study has employed a more elaborated conceptualization of schools' ethnic composition, as we examined both the impact of ethnic minority concentration and ethnic diversity/heterogeneity. We suggest that future research on the effects of compositional school features makes a clear distinction between these two ethnic composition variables. Furthermore, we go beyond a mechanical understanding of the association between the ethnic school composition and peer victimization, as we focused on the mediating relations-more specifically, on the role of interethnic school climate. We found that schools characterized by higher degrees of interethnic conflict evoke more peer victimization, and that interethnic conflict climate accounts for the impact of ethnic minority concentration on peer victimization in non-native pupils. However, while such aggregated climate variables are useful to understand how individual pupils are affected by structural school characteristics, they do not fully capture the motives of individual bullies. Hence, we suggest that future research should identify how the interethnic climate of the school is related to individual motives of perpetrators as well.

\section{Acknowledgments}

This article was made possible through funding from the Research Foundation Flanders (FWO-project G.040908). The authors would like to thank two anonymous referees for their constructive comments. Special thanks to Paul Mahieu, Anneloes Vandenbroucke, Ward Nouwen and Simon Boone for their helpful comments.

\section{References}

Agirdag, O. (2009). All languages welcomed here. Educational Leadership, 66, 20-25.

Agirdag, O. (2010). Exploring bilingualism in a monolingual school system: Insights from Turkish and native students from Belgian schools. British Journal of Sociology of Education, 31, 307-321.

Albertijn, M., \& Smeyers, M. (2009). [School in sight. Ten lessons from three years working on desegregation in education] School in zicht. Tien lessen uit drie jaar werken aan desegregatie in het onderwijs. Antwerpen: Tempera.

Ando, M., Asakura, T., \& Simons-Morton, B. (2005). Psychosocial influences on physical, verbal and indirect bullying among Japanese early adolescents. Journal of Early Adolescence, 25, 268-297.

Arora, C. M. J. (1996). Defining bullying-Towards a clearer general understanding and more effective intervention strategies. School Psychology International, $17,317-329$.

Bankston, C., \& Caldas, S. J. (1996). Majority African American schools and social injustice: The influence of de facto segregation on academic achievement. Social Forces, 75, 535-555. 
Blalock, H. M. (1967). Toward a theory of minority-group relations. New York: Wiley.

Bowers, L., Smith, P. K., \& Binney, V. (1992). Cohesion and power in the families of children involved in bully victim problems at school. Journal of Family Therapy, 14, 371-387.

Buhs, E. S., \& Ladd, G. W. (2001). Peer rejection as an antecedent of young children's school adjustment: An examination of mediating processes. Developmental Psychology, 37, 550-560.

Buhs, E. S., Ladd, G. W., \& Herald, S. L. (2006). Peer exclusion and victimization: Processes that mediate the relation between peer group rejection and children's classroom engagement and achievement? Journal of Educational Psychology, 98, 1-13.

Burgess, S., Wilson, D., \& Lupton, R. (2005). Parallel lives? Ethnic segregation in schools and neighbourhoods. Urban Studies, 42, 1027-1056.

Chan, W. Y., \& Birman, D. (2009). Cross-and same-race friendships of Vietnamese immigrant adolescents: A focus on acculturation and school diversity. International Journal of Intercultural Relations, 33, 313-324.

Dansby, M. R., \& Landis, D. (1996). The use of equal opportunity climate in intercultural training. In D. Landis, \& R. S. Bhagat (Eds.), Handbook of Intercultural Training. Thousand Oaks, CA: Sage.

Demanet, J. (2008). Populair of verstoten? Een netwerkanalytisch onderzoek naar de sociale kenmerken van pesters in het Vlaamse secundaire onderwijs [Popular or isolated? A network analytical study for the social characteristics of bullies in Flemish secondary schools]. Tijdschrift voor sociologie, 29, 397-423.

Driessen, G. (2002). School composition and achievement in primary education: A large-scale multilevel approach. Studies in Educational Evaluation, 28, 347-368.

Erikson, R., Goldthorpe, J. H., \& Portocarero, L. (1979). Intergenerational Class Mobility in 3 Western European Societies - England, France and Sweden. British Journal of Sociology, 30, 415-441.

Espelage, D. L., \& Swearer, S. M. (2003). Research on school bullying and victimization: What have we learned and where do we go from here? School Psychology Review, 32, 365-383.

Felouzis, G. (2005). Ethnic segregation and its effects in middle school in France. Revue Francaise De Sociologie, 46, 3-35.

Fischer, M. J. (2008). Does campus diversity promote friendship diversity? A look at interracial friendships in college. Social Science Quarterly, 89, 631-655.

Goldsmith, P. A. (2004). School's role in shaping race relations: Evidence on friendliness and conflict. Social Problems, 51, 587-612.

Graham, S. (2006). Peer victimization in school: Exploring the ethnic context. Current Directions in Psychological Science, 15, $317-321$.

Gray-Little, B., \& Hafdahl, A. R. (2000). Factors influencing racial comparisons of self-esteem: A quantitative review. Psychological Bulletin, 126, 26-54.

Hanish, L. D., \& Guerra, N. G. (2000). The roles of ethnicity and school context in predicting children's victimization by peers. American Journal of Community Psychology, 28, 201-223.

Hawley, P. H. (1999). The ontogenesis of social dominance: A strategy-based evolutionary perspective. Developmental Review, 19, 97-132.

Jacobs, D., Rea, A., \& Teney, C. (2009). [The social lift remains stabbing. The performance of immigrant pupils in the Flemish Community and the French Community] De sociale lift blijft steken. De prestaties van allochtone leerlingen in de Vlaamse Gemeenschap en de Franse Gemeenschap. Brussel: Koning Boudewijnstichting.

Juvonen, J., Nishina, A., \& Graham, S. (2001). Self-views versus peer perceptions of victim status among early adolescents. In J. Juvonen, \& S. Graham (Eds.), Peer harassment in school: The plight of the vulnerable and victimized (2nd ed., pp. 105-124). New York: Guilford Press.

Juvonen, J., Nishina, A., \& Graham, S. (2006). Ethnic diversity and perceptions of safety in urban middle schools. Psychological Science, 17, 393-400.

Kasen, S., Johnson, J., \& Cohen, P. (1990). The impact of school emotional climate on student psychopathology. Journal of Abnormal Child Psychology, 18, $165-177$.

Kristen, C. (2005). School choice and ethnic school segregation: Primary school selection in Germany. Münster: Waxmann Verlag.

Kuperminc, G. P., Leadbeater, B. J., \& Blatt, S. J. (2001). School social climate and individual differences in vulnerability to psychopathology among middle school students. Journal of School Psychology, 39, 141-159.

Kuperminc, G. P., Leadbeater, B. J., Emmons, C., \& Blatt, S. J. (1997). Perceived school climate and difficulties in the social adjustment of middle school students. Applied Developmental Science, 1, 76-88.

Lancee, B., \& Dronkers, J. (2010). Ethnic, religious and economic diversity in the neighbourhood: explaining quality of contact with neighbours, trust in the neighbourhood and inter-ethnic trust for immigrant and native residents. Journal of Ethnic and Migration Studies (Forthcoming).

Longshore, D. (1982). Race composition and white hostility - A research note on the problem of control in desegregated schools. Social Forces, 61, 73-78.

Mahieu, P. (2002). Desegregatie in functie van integratie. In C. Timmerman, P. Hermans, \& J. Hoornaert (Eds.), Allochtone jongeren in het onderwijs. Een multidisciplinair perspectief (pp. 205-232). Leuven: Garant.

Nadeem, E., \& Graham, S. (2005). Early puberty, peer victimization, and internalizing symptoms in ethnic minority adolescents. Journal of Early Adolescence, $25,197-222$.

O'Moore, M, \& Kirkham, C. (2001). Self-esteem and its relationship to bullying behaviour. Aggressive Behavior, 27, $269-283$.

Putnam, R. D. (2007). E pluribus unum: Diversity and community in the twenty-first century The 2006 Johan Skytte Prize Lecture. Scandinavian Political Studies, 30, 137-174.

Rowe, D. C., Almeida, D. M., \& Jacobson, K. C. (1999). School context and genetic influences on aggression in adolescence. Psychological Science, 10, 277-280.

Rumberger, R. W., \& Palardy, G. J. (2005). Does segregation still matter? The impact of student composition on academic achievement in high school. Teachers College Record, 107, 1999-2045.

Singer, J. D. (1998). Using SAS PROC MIXED to fit multilevel models, hierarchical models, and individual growth models. Journal of Educational and Behavioral Statistics, 23, 323-355.

Szulkin, R, \& Jonsson, O. J. (2006). Ethnic segregation and educational outcomes in Swedish comprehensive schools: A multilevel analysis. NEP: New Economic Papers.

Teddlie, C., \& Reynolds, D. (2000). The international handbook of school effectiveness research. London: Falmer Press.

Van Houtte, M. (2005). Climate or culture? A plea for conceptual clarity in school effectiveness research. School Effectiveness and School Improvement, 16, 71-89.

Van Houtte, M., \& Stevens, P. A. J. (2009). School ethnic composition and students' integration outside and inside schools in Belgium. Sociology of Education, $82,217-239$.

Verkuyten, M., \& Thijs, J. (2002). Racist victimization among children in The Netherlands: The effect of ethnic group and school. Ethnic and Racial Studies, $25,310-331$

Vervoort, M., Scholte, R., \& Overbeek, G. (2010). Bullying and victimization among adolescents: The role of ethnicity and ethnic composition of school class. Journal of Youth and Adolescence, 39, 1-11.

Westerbeek, K. (1999). The colours of my classroom: A study into the effects of the ethnic composition of classrooms on the achievement of pupils from different ethnic backgrounds. Florence: European University Institute.

Wright, J. C., Giammarino, M., \& Parad, H. W. (1986). Social-status in small-groups - Individual-group similarity and the social misfit. Journal of Personality and Social Psychology, 50, 523-536. 